Short Communication

\title{
Exposure to an extremely low-frequency electromagnetic field only slightly modifies the proteome of Chromobacterium violaceum ATCC 12472
}

\author{
Rafael A. Baraúna ${ }^{1}$, Agenor V. Santos ${ }^{1}$, Diego A. Graças ${ }^{1}$, Daniel M. Santos ${ }^{2}$, Rubens Ghilardi Júnior ${ }^{3}$, \\ Adriano M. C. Pimenta ${ }^{2}$, Marta S. P. Carepo ${ }^{4}$, Maria P.C. Schneider ${ }^{1}$ and Artur Silva ${ }^{1}$ \\ ${ }^{1}$ Laboratório de Polimorfismo de DNA, Instituto de Ciências Biológicas, \\ Universidade Federal do Pará, Belém, PA, Brazil. \\ ${ }^{2}$ Laboratório de Venenos e Toxinas, Instituto de Ciências Biológicas, \\ Universidade Federal de Minas Gerais, Belo Horizonte, MG, Brazil. \\ ${ }^{3}$ Superintendência do Meio Ambiente, Centrais Elétricas do Norte do Brasil S/A, Brasília, DF, Brazil. \\ ${ }^{4}$ Rede de Química e Tecnologia, Centro de Química Fina e Biotecnologia, Departamento de Química, \\ Faculdade de Ciências e Tecnologia, Universidade Nova de Lisboa, Caparica, Portugal.
}

\begin{abstract}
Several studies of the physiological responses of different organisms exposed to extremely low-frequency electromagnetic fields (ELF-EMF) have been described. In this work, we report the minimal effects of in situ exposure to ELF-EMF on the global protein expression of Chromobacterium violaceum using a gel-based proteomic approach. The protein expression profile was only slightly altered, with five differentially expressed proteins detected in the exposed cultures; two of these proteins (DNA-binding stress protein, Dps, and alcohol dehydrogenase) were identified by MS/MS. The enhanced expression of Dps possibly helped to prevent physical damage to DNA. Although small, the changes in protein expression observed here were probably beneficial in helping the bacteria to adapt to the stress generated by the electromagnetic field.
\end{abstract}

Keywords: C. violaceum, electromagnetic field, proteomic analysis.

Received: August 11, 2014; Accepted: November 30, 2014.

Various biological effects of extremely low-frequency electromagnetic fields (ELF-EMF) $(<0.05 \mathrm{mT})$ in living organisms have been reported (Berg, 1999; Fojt et al., 2004). However, the biological peculiarities of each organism analyzed and the different experimental conditions used have made it difficult to establish the effects of ELFEMF in biological systems (Fojt et al., 2004, 2009; Di Campli et al., 2010). Moreover, the increasing use of electric and electronic appliances heightens the need to clarify the effects of such interference. In addition, there is a growing investment in projects related to the generation of electricity through natural sources such as hydroelectric power plants (HPP) that require an extensive network of urban and rural transmission lines that consequently generate ELFEMF.

Only a few investigations into the effects of ELFEMF on bacterial cells have been undertaken (Cellini et al., 2008; Huwiler et al., 2012), despite the fact that their short cell cycle and easy handling make bacteria a good model

Send correspondence to Artur Silva. Laboratório de Polimorfismo de DNA, Instituto de Ciências Biológicas, Universidade Federal do Pará, Rua Augusto Corrêa 1, 66075-210 Belém, PA, Brazil, E-mail: asilva@ufpa.br. organism for this type of study. Chromobacterium violaceum is a free-living bacterium that has been isolated from diverse tropical and subtropical environments around the world (Lima-Bittencourt et al., 2011; Ponnusamy et al., 2011). The genome of strain ATCC 12472 has been sequenced and analyzed by the Brazilian National Genome Consortium (Brazilian National Genome Project Consortium, 2003) and knowledge of its genetic repertoire has led to more detailed studies of the biology of this microorganism (Stauff and Bassler, 2011; Silva-Rocha et al., 2013; Castro-Gomes et al., 2014). Chromobacterium violaceum ATCC 12472 has also been tested and analyzed under various stress conditions using high-throughput screening technologies (HTST) such as two dimensional difference gel electrophoresis (2D-DIGE) coupled with mass spectrometry (2D-DIGE-MS/MS) (Baraúna et al., 2011; Ciprandi et al., 2012). The large amount of molecular data generated by this approach provides a basis for the use of $C$. violaceum as a model organism to evaluate biological responses to the magnetic field in prokaryotes. Proteomics provides a useful means of detecting changes in global protein expression and generates crucial information for the identification of new biological targets after exposure to ELF-EMF 
(Wittmann-Liebold et al., 2006; Leszczynski et al., 2012). Technological advances and the importance of omics techniques in ELF-EMF research are indispensable and were emphasized by the World Health Organization and the Radiation and Nuclear Safety and Authority at meetings held in Helsinki, Finland in 2005 (Leszczynski and Meltz, 2006). The aim of this study was to use 2D-DIGE-MS/MS to examine the ability of an electromagnetic field generated by transmission lines to modify the in situ expression profile of C. violaceum ATCC 12472 at a selected point of the bacterial growth curve.

For bacterial exposure, pre-inocula grown overnight in LB medium were standardized to an optical density at $720 \mathrm{~nm}\left(\mathrm{OD}_{720}\right)$ of 0.04 and exposed to ELF-EMF. The $C$. violaceum cells were exposed in situ in a stable environment at the Regional Transmission Station of Pará belonging to Northern Brazil Power Plants S/A (Regional de Transmissão do Pará das Centrais Elétricas do Norte do Brasil S/A - Eletronorte). Flasks containing $50 \mathrm{~mL}$ cultures were kept either near the station exit fence (control group) or below the breakers formed by the $500 \mathrm{kV}$ transmission lines of the Tucuruí Hydroelectric Plant (treated group) and were exposed for $7 \mathrm{~h}$ without agitation. The electromagnetic field was monitored using an electromagnetic field radiation detector (EMF tester, Lutron). The OD of the samples, used as an indicator of bacterial density, was determined with a Novaspec II spectrophotometer at $720 \mathrm{~nm}$ (Pharmacia Biotech). The experiment was carried out in biological triplicate for each condition (control and treated groups) being run on each occasion.

After exposure, cultures were centrifuged (5,000 x $g$, $10 \mathrm{~min}, 4^{\circ} \mathrm{C}$ ) and the cell pellets were washed with $50 \mathrm{mM}$ Tris- $\mathrm{HCl}, \mathrm{pH} 7.5$ and resuspended in a lysis solution $(7 \mathrm{M}$ urea, $2 \mathrm{M}$ thiourea, $4 \%$ CHAPS, $50 \mathrm{mM}$ DTT, $40 \mathrm{mM}$ Tris-HCl, $\mathrm{pH}$ 7.5) containing a protease inhibitor cocktail (Roche). The bacteria were sonicated and the resulting lysate was centrifuged $\left(21,000 \mathrm{~g}, 1 \mathrm{~h}, 4{ }^{\circ} \mathrm{C}\right)$. The supernatant containing solubilized proteins was stored at $-70{ }^{\circ} \mathrm{C}$ until used. Samples were quantified using a 2D Quant kit (GE Healthcare) according to the manufacturer's protocol.

Following protein precipitation by the methanol/chloroform method (Wessel and Flügge, 1984), $54 \mu \mathrm{g}$ of protein from each sample was labeled with either $400 \mathrm{pmol}$ of $\mathrm{Cy} 3$ (control) or Cy5 (treated) dyes for $30 \mathrm{~min}$ and the reactions were stopped by adding $10 \mathrm{mM} \mathrm{L}$-lysine. All labeling procedures were done on ice and protected from light. A mixture of all replicates corresponding to $54 \mu \mathrm{g}$ of protein was used as an internal control and labeled with Cy2. Subsequently, samples for each condition and the internal control were mixed, diluted with rehydration buffer (7 M urea, $2 \mathrm{M}$ thiourea, 2\% CHAPS, $0.002 \%$ bromophenol blue, $0.5 \%$ IPG buffer, $50 \mathrm{mM}$ DTT) and applied to immobilized $\mathrm{pH}$ gradient (IPG) strips $(24 \mathrm{~cm}$ ) of $\mathrm{pH}$ 4-7 (GE Healthcare), according to the manufacturer's protocol. Three replicates from independent cultures were analyzed. The strips were rehydrated with each sample for $16 \mathrm{~h}$ at room temperature. Isoelectric focusing (IEF) was done using an Ettan IPGphor II apparatus (GE Healthcare) at a total of $115,599 \mathrm{Vh}$ for $18 \mathrm{~h}$. After IEF, the strips were equilibrated and transferred to the top of a $12.5 \%$ polyacrylamide gel and the second dimension was run in an Ettan DALTsix system (GE Healthcare) at $5 \mathrm{~W}$ per gel for $30 \mathrm{~min}$ and then at $17 \mathrm{~W}$ per gel until the bromophenol blue reached the bottom of the gel.

Images of DIGE gels were obtained using an Ettan DIGE Imager scanner and analyzed with Image Master 2D Platinum software v.7.0 (all from GE Healthcare). Spot detection was done automatically. Spots with an average relative volume of \pm 1.3 -fold were considered to be differentially expressed. ANOVA was used to assess the significance of the changes in expression, with $p<0.05$ indicating significance. After expression analysis, preparative gels containing $450 \mu \mathrm{g}$ of protein were stained with colloidal Coomassie blue and subsequently used for digestion and identification of differentially expressed protein spots. The images of the preparative gels were aligned with those obtained for the 2D-DIGE analytical gels in the Image Master 2D Platinum program to ensure correct recovery of the differentially expressed spots.

The spots of interest were manually excised from the preparative gels, dehydrated with acetonitrile and incubated with trypsin solution ( $50 \mathrm{mM}$ ammonium bicarbonate, $10 \mathrm{mM}$ acetic acid and trypsin $20 \mathrm{ng} / \mu \mathrm{L}$ ) (Promega) for $1 \mathrm{~h}$ on ice. Excess trypsin solution was removed with a pipette and the peptides were digested at $58{ }^{\circ} \mathrm{C}$ for $30 \mathrm{~min}$. Subsequently, the digested peptides were extracted from the gels with an ultrasonicator following the addition of $30 \mu \mathrm{L}$ of $30 \%$ formic acid and $50 \%$ acetonitrile. The sample was concentrated to approximately $10 \mu \mathrm{L}$ in a SpeedVac and desalted with a ZipTip (Millipore). For identification, the samples were mixed at a 1:1 ratio with $\alpha$-cyano-4hydroxycinnamic acid (CHCA) matrix (Sigma) and transferred to the Anchorchip 600 plate of a MALDI-TOF/TOF AutoflexIII (Bruker Daltonics). All spectra were measured in the positive reflector mode. Spectra obtained by this procedure were analyzed using the Mascot server (http://www.matrixscience.com) and compared with the genomic information of the Proteobacteria group deposited in the NCBI nr database (http://www.ncbi.nlm.nih.gov). MS and MS/MS spectra for the identified proteins are shown in Figure S1.

The strength of the electromagnetic field in the control and treated cultures was $0.02 \mu \mathrm{T}$ and $0.66 \mu \mathrm{T}$, respectively, such that the exposure was $>30$ times greater in the bacterial cultures near the transmission line; the latter cultures also had a higher bacterial density (greater $\mathrm{OD}_{720}$ ) at the time of extraction $(\mathrm{p}<0.05)$ (Figure $\mathrm{S} 2)$. In contrast to these findings, studies using different strains of $E$. coli have found no difference in growth when cells were exposed to 
Table 1 - Chromobacterium violaceum proteins that were differentially expressed during exposure to an electromagnetic field and identified by MS/MS.

\begin{tabular}{lccclcl}
\hline Match ID & Locus tag & Protein accession no. & Mascot score & Protein name & Theoretical pI/MW (Da) & Matched peptides \\
\hline 394 & CV_2728 & 34498183 & 51 & Alcohol dehydrogenase & $6.12 / 39190$ & $\begin{array}{l}\text { K.AVELIAGFLRR.A } \\
\text { R.LAADVGIPAGLR.E }\end{array}$ \\
458 & CV_4253 & 34499708 & 112 & $\begin{array}{l}\text { DNA-binding stress } \\
\text { protein }\end{array}$ & $5.59 / 17456$ & R.ALGHYAPGSYADYAK.L \\
\hline
\end{tabular}

an electromagnetic field (Mittenzwey et al., 1996; Cellini et al., 2008; Huwiler et al., 2012).

The proteomic analysis detected five spots that were differentially expressed in the cultures near the breaker. Of these, one spot was down-regulated and four were upregulated (Figure 1 and Table 1); two of these five spots were identified by MS/MS as DNA-binding stress protein (Dps) and alcohol dehydrogenase (Table 1 and Figure S1). These results showed that the exposure of $C$. violaceum to ELF-EMF under the conditions described here caused minimal changes in the bacterial protein expression profile. The two proteins identified here were related to DNA protection and cellular metabolism.

The importance of the versatile Dps protein family in various types of stress, including acidic and oxidative stress, as well as in the physical protection of DNA molecules, has been described (Martinez and Kolter, 1997; Haikarainen and Papageorgiou, 2010; Calhoun and Kwon, 2011). Bacteria have a well-developed mechanism for protecting DNA from physical damage during stress and during exponential growth Dps expression is up-regulated by the hydrogen peroxide-inducible gene activator OxyR, a regulator also found in the genome of $C$. violaceum. The other overexpressed protein was alcohol dehydrogenase. The enhanced expression of this enzyme was most likely

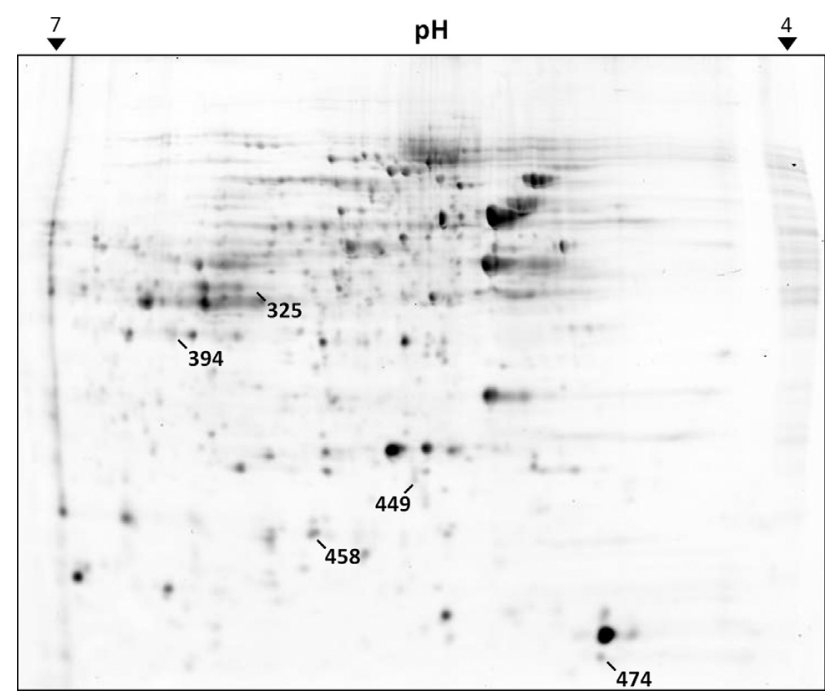

Figure 1 - 2D-DIGE gel of C. violaceum bacteria exposed to a low frequency electromagnetic field. The differential spots are indicated by their Match ID. Spot 325 was down-regulated while the others were up-regulated. The scale above the gel indicates the $\mathrm{pH}$ range used in the first dimension of 2D-DIGE. related to an increase in energy production by the bacteria to regenerate $\mathrm{NAD}^{+}$and was probably related to the greater bacterial growth in the presence of a $0.66 \mu \mathrm{T}$ magnetic field (Figure S2).

Similar findings to those described here were reported for peripheral human blood lymphocytes and Saccharomyces cerevisiae strain DBY747 exposed to electromagnetic fields ranging from 1 to $100 \mu \mathrm{T}$ (Luceri et al., 2005). There were no DNA strand breaks in either of these cell types, nor was there any variation in the gene expression profile as assessed by microarray experiments (Luceri et al., 2005). Despite the minor influence that ELF-EMF had on global gene expression in C. violaceum, certain proteins showed significant changes in their expression levels. Other organisms have also shown only minor physiological and molecular changes after exposure to ELF-EMF. For example, there was a decrease in the viability of Helicobacter pylori after exposure to ELF-EMF (Di Campli et al., 2010), whereas Salmonella enterica subsp. enterica serovar Hadar showed overexpression of the genes rpoA, katN, and dnaK (El May et al., 2009). To date, few studies have used omics techniques to evaluate the gene expression profile of organisms exposed to electromagnetic fields. As shown here using a proteomic approach, the global gene expression of $C$. violaceum was only slightly altered when the bacteria were exposed to ELF-EMF.

\section{Acknowledgments}

This work was supported by Coordenação de Aperfeiçoamento de Pessoal de Nível Superior (CAPES), Conselho Nacional de Desenvolvimento Científico e Tecnológico (CNPq), Agência Nacional de Energia Elétrica (ANEEL) and Centrais Elétricas do Norte do Brasil S/A (Eletronorte).

\section{References}

Baraúna RA, Ciprandi A, Santos AV, Carepo MSP, Gonçalves EC, Schneider MPC and Silva A (2011) Proteomics analysis of the effects of cyanate on Chromobacterium violaceum metabolism. Genes 2:736-747.

Berg H (1999) Problems of weak electromagnetic field effects in cell biology. Bioelectrochem Bioenerg 48:355-360.

Brazilian National Genome Project Consortium (2003) The complete genome sequence of Chromobacterium violaceum reveals remarkable and exploitable bacterial adaptability. Proc Natl Acad Sci USA 100:11660-11665. 
Calhoun LN and Kwon YM (2011) Structure, function and regulation of the DNA-binding protein Dps and its role in acid and oxidative stress resistance in Escherichia coli: A review. J Appl Microbiol 110:375-386.

Castro-Gomes T, Cardoso MS, DaRocha WD, Laibida LA, Nascimento AMA, Zuccherato LW, Horta MF, Bemquerer MP and Teixeira SMR (2014) Identification of secreted virulence factors of Chromobacterium violaceum. J Microbiol 52:350-353.

Cellini L, Grande R, Di Campli E, Di Bartolomeo S, Di Giulio M, Robuffo I, Trubiani O and Mariggiò MA (2008) Bacterial response to the exposure of $50 \mathrm{~Hz}$ electromagnetic fields. Bioelectromagnetics 29:302-311.

Ciprandi A, Baraúna RA, Santos AV, Gonçalves EC, Carepo MSP, Schneider MPC and Silva A (2012) Proteomic response to arsenic stress in Chromobacterium violaceum. $\mathrm{J}$ Integr OMICS 2:69-73.

Di Campli E, Di Bartolomeo S, Grande R, Di Giulio M and Cellini L (2010) Effects of extremely low-frequency electromagnetic fields on Helicobacter pylori biofilm. Curr Microbiol 60:412-418.

El May A, Snoussi S, Miloud NB, Maatouk I, Abdelmelek H, Aïssa RB and Landoulsi A (2009) Effects of static magnetic field on cell growth, viability, and differential gene expression in Salmonella. Foodborne Pathog Dis 6:547-552.

Fojt L, Klapetek P, Strasák L and Vetterl V (2009) 50 Hz magnetic field effect on the morphology of bacteria. Micron 40:918-922.

Fojt L, Strasák L, Vetterl V and Smarda J (2004) Comparison of the low-frequency magnetic field effects on bacteria Escherichia coli, Leclercia adecarboxylata and Staphylococcus aureus. Bioelectrochemistry 63:337-341.

Haikarainen T and Papageorgiou AC (2010) Dps-like proteins: Structural and functional insights into a versatile protein family. Cell Mol Life Sci 67:341-351.

Huwiler SG, Beyer C, Fröhlich J, Hennecke H, Egli T, Schürmann D, Rehrauer H and Fischer HM (2012) Genome-wide transcription analysis of Escherichia coli in response to extremely low-frequency magnetic fields. Bioelectromagnetics 33:488-496.

Leszczynski D and Meltz ML (2006) Questions and answers concerning applicability of proteomics and transcriptomics in EMF research. Proteomics 6:4674-4677.

Leszczynski D, Pomerai D, Koczan D, Stoll D, Franke H and Albar JP (2012) Five years later: The current status of the use of proteomics and transcriptomics in EMF research. Proteomics 12:2493-2509.

Lima-Bittencourt CI, Costa PS, Hollatz C, Raposeiras R, Santos FR, Chartone-Souza E and Nascimento AMA (2011) Com- parative biogeography of Chromobacterium from the neotropics. Antonie van Leeuwenhoek 99:355-370.

Luceri C, Filippo C, Giovannelli L, Blangiardo M, Cavalieri D, Aglietti F, Pampaloni M, Andreuccetti D, Pieri L, Bambi F, et al. (2005) Extremely low-frequency electromagnetic fields do not affect DNA damage and gene expression profiles of yeast and human lymphocytes. Radiat Res 164:277285.

Martinez A and Kolter R (1997) Protection of DNA during oxidative stress by the nonspecific DNA-binding protein Dps. J Bacteriol 179:5188-5194.

Mittenzwey R, Süßmuth R and Mei W (1996) Effects of extremely low-frequency electromagnetic fields on bacteria The question of a co-stressing factor. Bioelectrochem Bioenerg 40:21-27.

Ponnusamy K, Jose S, Savarimuthu I, Michael GP and Redenbach M (2011) Genetic diversity study of Chromobacterium violaceum isolated from Kolli hills by amplified ribosomal DNA restriction analysis (ARDRA) and random amplified polymorphic DNA (RAPD). Lett Appl Microbiol 53:341349.

Silva-Rocha R, Azevedo JSN, Carepo MSP, Souza RL, Silva A, de Lorenzo V and Schneider MPC (2013) Vestigialization of arsenic resistance phenotypes/genotypes in Chromobacterium violaceum strains thriving in pristine Brazilian sites. Biocatal Biotransfor 31:281-291.

Stauff DL and Bassler BL (2011) Quorum sensing in Chromobacterium violaceum: DNA recognition and gene regulation by the CviR receptor. J Bacteriol 193:3871-3878.

Wessel D and Flügge UI (1984) A method for the quantitative recovery of protein in dilute solution in the presence of detergents and lipids. Anal Biochem 138:141-143.

Wittmann-Liebold B, Graack HR and Pohl T (2006) Twodimensional gel electrophoresis as tool for proteomics studies in combination with protein identification by mass spectrometry. Proteomics 6:4688-4703.

\section{Supplementary Material}

The following online material is available for this article: Figure S1 - MS and MS/MS spectra generated for spots 394 (a) and 458 (b).

Figure S2 - Cell density and protein concentration of control and exposed cultures.

This material is available as part of the online article from: http://www.scielo.br/gmb.

Associate Editor: Carlos R. Machado

License information: This is an open-access article distributed under the terms of the Creative Commons Attribution License, which permits unrestricted use, distribution, and reproduction in any medium, provided the original work is properly cited. 